\title{
Application of phosphatidylethanol (PEth) in whole blood in comparison to ethyl glucuronide in hair (hEtG) in driving aptitude assessment (DAA)
}

Authors:

Alexandra Schröck ${ }^{1}$, Matthias Pfäffli ${ }^{2}$, Stefan König $^{1}$, Wolfgang Weinmann ${ }^{1}$

Affiliation:

${ }^{1}$ Institute of Forensic Medicine, Forensic Toxicology and Chemistry, University of Bern, Switzerland

${ }^{2}$ Institute of Forensic Medicine, Department of Traffic Sciences, University of Bern, Switzerland

Corresponding author:

Alexandra Schröck

Institute of Forensic Medicine, University of Bern

Bühlstrasse 20

3012 Bern

Switzerland

Tel. +41(0)316313050

E-Mail: alexandra.schroeck@irm.unibe.ch

\section{Acknowledgement}

We would like to thank the team of the Department of Traffic Sciences of the Institute of Forensic Medicine Bern for collecting the blood and hair samples for comparison of PEth in blood and EtG in hair (hEtG) in driving aptitude assessment, and we would like to thank Anja Kaiser, Nadja Utiger, Sidonia Guggisberg, Anita Iannone, Severine Krönert and Thomas Wüthrich from our institute for the determination of ethyl glucuronide in hair.

\section{Funding}

This study was supported by the Swiss Foundation of Alcohol Research (Grant 254/2014: Studies on phosphatidylethanol (PEth) - a promising biomarker for the detection of harmful ethanol consumption - and its possible use for abstinence monitoring). 


\section{Abstract}

For driving aptitude assessment (DAA), the analysis of several alcohol biomarkers is essential for the detection of alcohol intake besides psycho-medical exploration.

In Switzerland, EtG in hair $(\mathrm{hEtG})$ is often the only direct marker for abstinence monitoring in DAA. Therefore, the suitability of phosphatidylethanol (PEth) was investigated as additional biomarker.

PEth 16:0/18:1 and 16:0/18:2 were determined by online-SPE-LC-MS/MS in 136 blood samples of persons undergoing DAA and compared to $\mathrm{hEtG}$, determined in corresponding hair segments.

With a PEth 16:0/18:1 threshold of $210 \mathrm{ng} / \mathrm{mL}$ for excessive alcohol consumption, all $(\mathrm{n}=30)$ but one tested person also had $\mathrm{hEtG}$ values $\geq 30 \mathrm{pg} / \mathrm{mg}$. In 54 cases, results are not in contradiction to an abstinence as neither PEth $(<20 \mathrm{ng} / \mathrm{mL})$ nor $\mathrm{hEtG}(<7 \mathrm{pg} / \mathrm{mg})$ was detected. In 8 cases both markers showed moderate consumption. Altogether, PEth and $\mathrm{hEtG}$ were in accordance in $68 \%$ of the samples, although covering different time periods of alcohol consumption.

With receiver operating characteristic analysis, PEth was evaluated to differentiate abstinence, moderate and excessive alcohol consumption in accordance with $\mathrm{hEtG}$ limits. A PEth 16:0/18:1 threshold of $150 \mathrm{ng} / \mathrm{mL}$ resulted in the best sensitivity (70.6\%) and specificity (98.8\%) for excessive consumption. Values between $20-150 \mathrm{ng} / \mathrm{mL}$ passed for moderate consumption, values $<20 \mathrm{ng} / \mathrm{mL}$ passed for abstinence.

As PEth mostly has a shorter detection window (2-4 weeks) than hEtG (up to 6 months depending on hair length), changes in drinking behavior can be detected earlier by PEth than by $\mathrm{hEtG}$ analysis alone. Therefore, PEth helps to improve the diagnostic information and is a valuable additional alcohol marker for DAA.

\section{Keywords}

Phosphatidylethanol (PEth) in blood, Alcohol biomarker, Ethyl glucuronide in hair (hEtG), Online-SPE-LC-MS/MS 


\section{Introduction}

In Switzerland, administrative regulations require a driving aptitude assessment (DAA) for convicted driving under the influence (DUI) of alcohol offenders having a blood alcohol concentration of $1.6 \%$ and higher, as prolonged excessive alcohol misuse is suspected above this limit $[1,2]$. In consequence of a DUI of alcohol offence, the driver's license is revoked. The driver has to pass a DAA, in which the driver's alcohol consumption habits are evaluated. Generally, the affected persons have to prove abstinence over a time period of 6 months (after traffic relevant alcohol misuse) up to 12 months (alcohol dependency) prior to re-granting the driver's license, and after re-granting the driver's license, minimal 12 months of a controlled alcohol abstinence are stipulated [3].

For DAA direct (ethyl glucuronide EtG, ethyl sulfate EtS, fatty acid ethyl esters FAEE) and indirect markers (carbohydrate deficient transferrin CDT, $\gamma$-glutamyl transferase GGT, mean corpuscular volume MCV, aspartate aminotransferase ASAT, alanine aminotransferase ALAT) are used [4]. However, EtG in hair (hEtG) often is the only direct marker for abstinence monitoring during DAA in Switzerland.

Hair samples mainly consist of head hair from the posterior region $(0-5 \mathrm{~cm})$ of the scalp, sometimes also from arms, legs and chest.

EtG is a non-volatile, water-soluble metabolite of ethanol (figure 1) [5]. It is formed by a nonoxidative phase II metabolism, catalyzed enzymatically by UDP-glucuronosyl transferases, which conjugates ethanol with activated glucuronic acid [6]. This reaction constitutes only a very small fraction $(<0.1 \%)$ of the ingested alcohol dose $[7,8]$. Depending on the amount of consumed alcohol EtG is detectable in blood, urine, tissues, sweat and hair long time after termination of ethanol elimination $[5,9]$.

Compared to the smaller detection windows of EtG in body fluids, EtG is detectable for several months in hair depending on the hair length. Therefore, $\mathrm{hEtG}$ is of advantage for longterm abstinence monitoring in DAA. To differentiate prolonged excessive from moderate alcohol consumption the Society of Hair Testing (SOHT) proposes a threshold of $30 \mathrm{pg} / \mathrm{mg}$ hEtG. A threshold of $7 \mathrm{pg} / \mathrm{mg}$ is "non-contradicting to self-reported abstinence". This expression is used, as occasional alcohol consumption cannot always be excluded, and if samples less than $3 \mathrm{~cm}$ or greater than $6 \mathrm{~cm}$ are analyzed for EtG, the results should be interpreted with caution [8, 10-12].

A direct marker, which has also a potential in the field of abstinence monitoring, is phosphatidylethanol (PEth), as it is formed directly after alcohol intake [13, 14]. 
The term PEth represents a group of phospholipid homologues, which are ethyl-esters of phosphatidic acid (figure 1). These homologues have two fatty acid chains bound to the glycerol backbone in sn-1 and sn-2 position and phosphoethanol in sn-3 position. The fatty acid chains typically contain $14-22$ carbon atoms with $0-6$ double bonds $[15,16]$. PEth homologues are present in cell membranes [17] and are biosynthesized from phosphatidylcholine (PC) catalyzed by the enzyme phospholipase D (PLD) [18], as long as ethanol is present in the organism. Due to an elimination half-life of about four days [17], accumulation of PEth is observed after repeated drinking. Therefore, PEth has been discussed as marker for detection of prolonged excessive alcohol consumption in several studies [16, 19-23].

Furthermore, drinking studies $[14,24]$ with a repeated alcohol consumption leading to a blood alcohol concentration (BAC) of $1 \mathrm{~g} / \mathrm{kg}$ on each of five or ten subsequent days showed a correlation between degree of alcohol consumption and detected PEth concentrations. The potential of PEth in abstinence monitoring was shown in another drinking study: After a single drinking event leading to an estimated BAC of $1 \mathrm{~g} / \mathrm{kg}$ and followed by an abstinence period of two weeks, PEth was detectable for three up to twelve days [25].

In this study we investigate the suitability of PEth in blood as an additional diagnostic marker for the assessment of drinking behavior by comparing the PEth concentrations in whole blood with EtG in proximal hair segments of up to $5 \mathrm{~cm}$ length, which is used in routine analysis for DAA in Switzerland and in Germany.

\section{Material and methods}

\section{Study design}

Blood and corresponding hair samples were obtained from 136 persons undergoing DAA at the Department of Traffic Sciences of the Institute of Forensic Medicine at the University of Bern, Switzerland. Samples were collected between December 2014 and December 2015. Blood was taken on the same day as hair samples and was analyzed for PEth homologues 16:0/18:1 and 16:0/18:2 by a validated online-SPE-LC-MS/MS method [25]. Hair was analyzed for EtG by a modified LC-MS/MS method according to Kummer et al. [26]. Hair samples were stored at room temperature. Blood samples were stored at $4{ }^{\circ} \mathrm{C}$ prior to analysis and were analyzed one week after sampling at the latest. 


\section{Chemicals and materials}

PEth 16:0/18:1 and PEth 16:0/18:2 were provided by Avanti Polar Lipids (Alabaster, USA). EtG and deuterated EtG were purchased from Lipomed (Arlesheim, Switzerland). Ammonium acetate, acetone and dichloromethane were obtained from Merck (Darmstadt, Germany).

2-Propanol was obtained from Fisher Scientific (Loughborough, UK), methanol (MeOH) was from Biosolve BV (Valkenswaard, Netherlands) and acetonitrile (MeCN) was supplied by Agros Organics (New Jersey, USA). Formic acid (98 \%) was provided by Fluka (Switzerland). HPLC solvents were of gradient grade; all other solvents were of analytical grade.

$\mathrm{H}_{2} \mathrm{O}$ dest. was produced in-house with a Milli-Q water system from Millipore (Billerica, USA).

Deuterated standards were synthesized in our laboratory from phosphatidylcholine PC 16:0/18:1 and phosphatidylcholine PC 16:0/18:2, respectively, and $\mathrm{D}_{6}$-ethanol catalyzed by phospholipase D [1].

EDTA monovettes (volume $3.4 \mathrm{~mL}$ ) were obtained from Sarstedt (Nümbrecht, Germany). Lithium-heparinized whole blood, which was used as blank blood, was donated by volunteers who were abstinent from alcohol for at least 4 weeks. Blank hair samples were donated from teetotalers.

\section{Determination of PEth in whole blood}

PEth was analyzed in $200 \mu \mathrm{L}$ of whole blood by online-SPE-LC-MS/MS with a QTrap 3200 mass spectrometer (AB Sciex, Toronto, Canada). Analytical separation was performed by a Luna RP-C5 column, $50 \mathrm{~mm}$ x $2 \mathrm{~mm}, 5 \mu \mathrm{m}$ particle size (Phenomenex, Brechbühler, Schlieren, Switzerland) by gradient elution using ammonium acetate $(10 \mathrm{mM}) / \mathrm{MeCN}$ (30:70, $\mathrm{v} / \mathrm{v}$ ) and 2-propanol. The precise details of the validated method can be found in [25].

\section{Determination of EtG in hair}

EtG was determined in hair with a limit of quantification (LOQ) of $3 \mathrm{pg} / \mathrm{mg}$ by a validated modified LC-MS/MS method according to [26] with a Ultimate 3000 LC-system (Dionex, Thermo Fisher Scientific, Reinach, Switzerland) coupled to a QTrap 5500 mass spectrometer (AB Sciex, Toronto, Canada). This method is used for routine analysis in the accredited laboratory (ISO 17025) of the Institute of Forensic Medicine Bern for samples from DAA according to SGRM guidelines [3]. 
Briefly, approx. $30 \mathrm{mg}$ of hair was washed with 3 different solvents (4 mL each of $1 . \mathrm{H}_{2} 0,2$. acetone, 3. dichloromethane) by subsequent shaking for $4 \mathrm{~min}$ and removal of the solvent between washing steps. After $1 \mathrm{~h}$ of drying, the hair was grinded for $5 \mathrm{~min}(30 \mathrm{1} / \mathrm{s})$ with a ballmill (MM400, Retsch, Haan, Germany). The hair powder was extracted for $2 \mathrm{~h}$ by ultrasonication with $1 \mathrm{~mL}$ D5-EtG containing deionized $\mathrm{H}_{2} \mathrm{O}$. Further purification of the extract was achieved by SPE with Oasis Max cartridges (3cc/60 mg; Waters, Baden-Dättwil, Switzerland). The samples were analyzed in MRM mode with online preconcentration using a Hypercarb column, 3.0 x $2.1 \mathrm{~mm}, 5 \mu \mathrm{m}$ (Thermo Fisher Scientific, Reinach, Switzerland), and after switching a two way valve, back-flow elution to the analytical column Zorbax Eclipse, $50 \mathrm{~mm}$ x $4.6 \mathrm{~mm}, 1.8 \mu \mathrm{m}$ (Agilent, MSP Kofel, Zollikofen, Switzerland) and gradient elution. The following transitions were used: EtG: m/z 221/75 as quantifier and m/z 221/85 as qualifier. For the deuterated internal standard D5-EtG the transitions m/z 226/75 (quantifier) and $\mathrm{m} / \mathrm{z} 226 / 85$ (qualifier) were used.

\section{Statistic evaluation}

ROC analysis (receiver operating characteristic) was performed with GraphPad Prism 6 by classifying the PEth results into three groups depending on $\mathrm{hEtG}$ thresholds, suggested by the SOHT (hEtG $\geq 30 \mathrm{pg} / \mathrm{mg}$ : excessive alcohol consumption; $7 \mathrm{pg} / \mathrm{mg} \leq \mathrm{hEtG}<30 \mathrm{pg} / \mathrm{mg}$ : moderate alcohol consumption; hEtG $<7 \mathrm{pg} / \mathrm{mg}$ : "non-contradicting to self-reported abstinence") $[10,11]$.

\section{Results}

136 samples from persons undergoing DAA were analyzed. The controlled persons were between 19 and 78 years old (mean age: $42 \pm 15$ years), $88.2 \%$ were male (120 male, 16 female).

The PEth and hEtG results were distributed into three groups: Excessive alcohol consumption, moderate alcohol consumption and sobriety (abstinence from alcohol) according to the thresholds suggested by the SOHT [10,11] for hEtG. For PEth 16:0/18:1, the proposed thresholds (210 ng/mL and $20 \mathrm{ng} / \mathrm{mL})$ were obtained from a Swedish study [27] and from results of drinking studies [14, 24, 25], meaning that PEth 16:0/18:1 values below $20 \mathrm{ng} / \mathrm{mL}$ (LOQ of the method) were rated as consistent with abstinence, and PEth 16:0/18:1 values above $210 \mathrm{ng} / \mathrm{mL}$ were classified to excessive alcohol consumption. For PEth 16:0/18:2 the following thresholds were used: PEth 16:0/18:2 $\geq 100 \mathrm{ng} / \mathrm{mL}$ : excessive alcohol consumption; 
$20 \mathrm{ng} / \mathrm{mL} \leq$ PEth 16:0/18:2 < $100 \mathrm{ng} / \mathrm{mL}$ : moderate alcohol consumption; PEth 16:0/18:2 < $20 \mathrm{ng} / \mathrm{mL}$ : consistent with abstinence.

With hEtG analysis, excessive alcohol consumption was detected in $37.5 \%$ of the samples; and $44.1 \%$ of the samples were consistent with abstinence. Moderate alcohol consumption was detected in $18.4 \%$ of the samples. With PEth 16:0/18:1 elevated alcohol consumption was detected only in $22.8 \%$ of the samples, but $58.1 \%$ of the samples were already consistent with abstinence. Moderate alcohol consumption was detected in $19.1 \%$ of the samples.

29 of 30 persons with PEth 16:0/18:1 $\geq 210 \mathrm{ng} / \mathrm{mL}$ had $\mathrm{hEtG} \geq 30 \mathrm{pg} / \mathrm{mg}$. Only one person was classified into the group of excessive alcohol consumers by PEth analysis whereas hEtG indicated moderate consumption (PEth: $450 \mathrm{ng} / \mathrm{mL}, \mathrm{hEtG}: 29 \mathrm{pg} / \mathrm{mg}$ ).

In 54 cases neither PEth nor hEtG was detected. In 8 cases PEth was $20 \leq$ PEth $<210 \mathrm{ng} / \mathrm{mL}$, and hEtG was between 7 and $30 \mathrm{pg} / \mathrm{mg}$, both markers showing moderate alcohol consumption.

Nine tested persons showed excessive alcohol consumption after analyzing hEtG, but PEth in blood was negative. There were no tested persons with negative hEtG values and PEth values above the threshold for excessive alcohol consumption of $210 \mathrm{ng} / \mathrm{mL}$.

There was a little overlapping of different PEth and hEtG results between excessive and moderate alcohol consumption and between moderate alcohol consumption and abstinence. For example hEtG showed excessive alcohol consumption, but the corresponding PEth result showed moderate alcohol consumption $(8.8 \%)$, or hEtG showed moderate alcohol consumption, but PEth was not detectable $(11.8 \%)$. There were also tested persons with negative hEtG results, whereas PEth was detectable in blood, demonstrating moderate alcohol consumption (4.4\%). Thus, very recent alcohol consumption might have taken place, which could not be detected in hair, because of the gap of approximately 14 days that hair needs to grow out of the scalp before it can be cut. All results are summarized in detail in table 1.

As also the PEth homologue 16:0/18:2 was included in the column-switching LC-MS/MS method, this homologue was also compared to hEtG. Here a value of PEth 16:0/18:2 $\geq 100$ $\mathrm{ng} / \mathrm{mL}$ was used as threshold to differentiate excessive from moderate alcohol consumption. PEth 16:0/18:2 values below $20 \mathrm{ng} / \mathrm{mL}$ (LOQ of the method) were regarded as consistent with abstinence. With these thresholds, the distribution of results obtained by PEth 16:0/18:1 were close to the results obtained by hEtG. With PEth 16:0/18:2 elevated alcohol consumption was detected in $22.8 \%$ (hEtG: $37.5 \%$ ), abstinence was detected in $61.0 \%$ (hEtG: $44.1 \%$ ) and moderate alcohol consumption was detected in $16.2 \%$ (hEtG: $18.4 \%$ ) of the samples. 
For PEth 16:0/18:1 and 16:0/18:2, the used thresholds to differentiate abstinence, moderate and excessive alcohol consumption were evaluated by ROC analysis. Using the software GraphPad Prism 6, the PEth results were classified into three groups depending on hEtG (figure 2). All tested persons with $\mathrm{hEtG} \geq 30 \mathrm{pg} / \mathrm{mg}$ were assumed to have prolonged excessive drinking habits, persons with $\mathrm{hEtG}$ between $7-30 \mathrm{pg} / \mathrm{mg}$ were classified to moderate alcohol consumption and persons with hEtG $<7 \mathrm{pg} / \mathrm{mg}$ were assumed to be abstainers or at least there was no contradiction to abstinence.

Using the suggested "Swedish threshold" of PEth 16:0/18:1 $\geq 210 \mathrm{ng} / \mathrm{mL}$ for the differentiation of excessive from moderate alcohol consumption, there is a specificity of 98.8 $\%$ and a sensitivity of $58.8 \%$. With a specificity of $100 \%$ at a threshold of $470 \mathrm{ng} / \mathrm{mL}$, there is only a sensitivity of $45.1 \%$. For the differentiation of excessive from moderate alcohol consumption the PEth 16:0/18:1 threshold of $150 \mathrm{ng} / \mathrm{mL}$ resulted in the best sensitivity $(70.6$ $\%$ ) and specificity (98.8\%) (figure $3 \mathrm{~A}$ ).

For the differentiation of drinking habits ("non-contradicting self-reported abstinence" from "moderate alcohol consumption") the PEth 16:0/18:1 threshold of $20 \mathrm{ng} / \mathrm{mL}$ (LOQ) resulted in the best compromise for sensitivity $(67.1 \%)$ and specificity $(90.0 \%)$. With a specificity of $100 \%$ at a threshold of $87 \mathrm{ng} / \mathrm{mL}$, there is only a sensitivity of $53.9 \%$. Using the LOD of our method of $10 \mathrm{ng} / \mathrm{mL}$, there is a specificity of $86.7 \%$ and a sensitivity of $71.1 \%$ (figure $3 \mathrm{C}$ ). PEth 16:0/18:1 values between the suggested thresholds of $20 \mathrm{ng} / \mathrm{mL}$ and $150 \mathrm{ng} / \mathrm{mL}$ would pass for moderate alcohol consumption habits.

Using the suggested "threshold" of PEth 16:0/18:2 $\geq 100 \mathrm{ng} / \mathrm{mL}$, there is a specificity of 98.8 $\%$ and a sensitivity of $58.8 \%$. With a specificity of $100 \%$ at a threshold of $332 \mathrm{ng} / \mathrm{mL}$, there would only be a sensitivity of $33.3 \%$. For the differentiation of excessive from moderate alcohol consumption the PEth 16:0/18:2 threshold of $96 \mathrm{ng} / \mathrm{mL}$ resulted in the best sensitivity $(62.8 \%)$ and specificity $(98.8 \%)$ (figure $3 \mathrm{~B}$ ).

For the differentiation of abstinence from moderate alcohol consumption the PEth 16:0/18:2 threshold of $20 \mathrm{ng} / \mathrm{mL}$ (LOQ) resulted in the best compromise for sensitivity (63.2\%) and specificity $(90.0 \%)$. With a specificity of $100 \%$ at a threshold of $93 \mathrm{ng} / \mathrm{mL}$, there would only be a sensitivity of $44.7 \%$. Using the LOD of our method as threshold, which is $10 \mathrm{ng} / \mathrm{mL}$, there is a specificity of $88.3 \%$ and a sensitivity of $67.1 \%$ (figure $3 \mathrm{D}$ ). PEth 16:0/18:2 values between the suggested thresholds of $20 \mathrm{ng} / \mathrm{mL}$ and $96 \mathrm{ng} / \mathrm{mL}$ would pass for moderate alcohol consumption habits. 


\section{Discussion}

Although PEth and hEtG cover different time periods of alcohol consumption, PEth 16:0/18:1 (thresholds: $210 \mathrm{ng} / \mathrm{mL}$ and $20 \mathrm{ng} / \mathrm{mL}$ ) and $\mathrm{hEtG}$ results are in agreement in $68 \%$ of tested persons undergoing DAA. By comparing PEth 16:0/18:2 (thresholds: $100 \mathrm{ng} / \mathrm{mL}$ and 20 $\mathrm{ng} / \mathrm{mL}$ ) to $\mathrm{hEtG}, 66 \%$ of the samples are in agreement.

Using the thresholds resulting from ROC analysis, results are in agreement in $72 \%$ of the samples for PEth 16:0/18:1 (thresholds: $150 \mathrm{ng} / \mathrm{mL}$ and $20 \mathrm{ng} / \mathrm{mL}$ ) (see table 1: numbers in line 2 and 3 in italics), for PEth 16:0/18:2 $68 \%$ of the samples are in agreement in comparison to hEtG (PEth 16:0/18:2 thresholds: $96 \mathrm{ng} / \mathrm{mL}$ and $20 \mathrm{ng} / \mathrm{mL}$ ).

Of the tested persons, who were classified into the group with moderate alcohol consumption habits $(7 \mathrm{pg} / \mathrm{mg} \leq \mathrm{hEtG}<30 \mathrm{pg} / \mathrm{mg}$ ), only one person had a PEth 16:0/18:1 value above the threshold of $150 \mathrm{ng} / \mathrm{mL}$ (sensitivity: $70.6 \%$, specificity: $98.8 \%$ ) resulting from ROC analysis. However, the hEtG result is very close to be classified as excessive alcohol consumption (hEtG: $29 \mathrm{pg} / \mathrm{mg}$ and PEth: $450 \mathrm{ng} / \mathrm{mL}$ ). These results show that all PEth values above this threshold are representing excessive alcohol consumption habits with a specificity of $98.8 \%$, and that the PEth 16:0/18:1 threshold for differentiation of excessive and moderate alcohol consumption can be lowered to $150 \mathrm{ng} / \mathrm{mL}$ for persons undergoing DAA.

There is a relatively high number of persons undergoing DAA, who showed excessive alcohol consumption habits (37.5\% detected by hEtG analysis, $22.8 \%$ detected by PEth analysis). The reason for these findings could be that alcohol consumption habits were assessed soon after withdrawal of the driver's license, and drinking habits might not have been changed in the meantime.

The reasons for minor discrepancies between PEth and $\mathrm{hEtG}$ results are due to the different detection windows of the matrices and analytes utilized (blood: PEth, hair: EtG). As PEth has a shorter detection window (ca. 2 - 4 weeks) than hEtG (several months depending on the hair length) [8], changes in drinking behavior can be detected earlier by PEth than by hEtG analysis alone. Furthermore, PEth can be directly detected in blood a few hours after alcohol ingestion, whereas EtG first needs to be incorporated into the hair bulbus. As the scalp hair growth rate can vary from $0.6-1.5 \mathrm{~cm} /$ month [28] with an average rate of approximately 1 $\mathrm{cm} / \mathrm{month}$, and an additional time period for hair growth (of 10 - 14 days) has to take place until the incorporated EtG is found in the proximal segment of head hair, a segment of 5 - 6 $\mathrm{cm}$ length corresponds to a retrospective time window of approximately 6 months [3]. 
Therefore, PEth shows changes in drinking habits earlier than hEtG. Withdrawal or relapse to drinking can be shown directly after drinking or cessation of drinking by PEth analysis. Additional PEth analysis during DAA increases the sensitivity for uncovering alcohol consumption, although a single blood sampling cannot cover a six months period - which is the approximated period covered by EtG analysis with a $5 \mathrm{~cm}$ proximal hair segment.

\section{Conclusion}

PEth is a valuable additional marker for DAA and helps to improve diagnostic information. As PEth has a shorter detection window (ca. 2 - 4 weeks) than hEtG (of a $5 \mathrm{~cm}$ proximal hair segment: approximately 6 months), changes in drinking behavior can be detected earlier by PEth in blood than by hEtG analysis alone. Another advantage of PEth analysis is that unlike hair, blood is always available in sufficient amounts.

Therefore, we strongly recommend including the two most abundant PEth homologues in human blood, PEth 16:0/18:1 and PEth 16:0/18:2, in routine analysis for DAA. PEth should be analyzed in $2-3$ blood samples over 6 months, as elevated PEth concentrations would demonstrate a lack of abstinence which might cause, prior to re-granting the driver's license, a longer withdrawal or, after re-granting the driver's license, a new withdrawal for a noncompliant person. 
Tables and figures (in order of appearance in the text)<smiles>CCOC(O)C(C(=O)O)C(O)C(O)O</smiles>

EtG

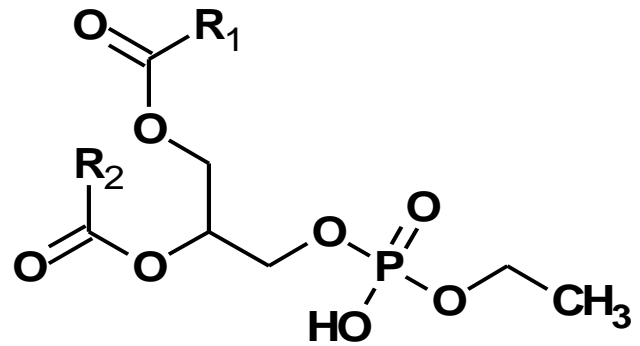

PEth

Figure 1. Structural formulas of ethyl glucuronide (EtG) and phosphatidylethanol (PEth); $\mathrm{R}_{1}$ and $\mathrm{R}_{2}$ : fatty-acyl-rests. 
Table 1. Classification of alcohol consumption habits using hEtG and PEth 16:0/18:1 from 136 tested persons undergoing DAA.

For PEth the following thresholds were used: PEth $<20 \mathrm{ng} / \mathrm{mL}$ : abstinence*; PEth $\geq 210$ $\mathrm{ng} / \mathrm{mL}$, and after ROC analysis PEth $\geq 150 \mathrm{ng} / \mathrm{mL}$ : excessive alcohol consumption.

\begin{tabular}{|c|c|c|c|}
\hline \multicolumn{2}{|c|}{ Drinking habits } & \multirow{2}{*}{$\begin{array}{c}\text { PEth } \geq 210 \mathrm{ng} / \mathrm{mL} \text {; } \\
\text { PEth }<20 \mathrm{ng} / \mathrm{mL} \\
\text { in \% } \\
\text { (number of samples) }\end{array}$} & \multirow{2}{*}{$\begin{array}{c}\text { PEth } \geq 150 \mathrm{ng} / \mathrm{mL} ; \\
\text { PEth }<20 \mathrm{ng} / \mathrm{mL} \\
\text { in \% } \\
\text { (number of samples) }\end{array}$} \\
\hline hEtG & PEth & & \\
\hline Excessive & Excessive & $\begin{array}{l}22.1 \\
(30)\end{array}$ & $\begin{array}{l}26.5 \\
(36)\end{array}$ \\
\hline Excessive & Moderate & $\begin{array}{c}8.8 \\
(12)\end{array}$ & $\begin{array}{l}4.4 \\
(6)\end{array}$ \\
\hline Moderate & Excessive & $\begin{array}{l}0.7 \\
(1)\end{array}$ & $\begin{array}{l}0.7 \\
(1)\end{array}$ \\
\hline Moderate & Moderate & $\begin{array}{l}5.9 \\
(8)\end{array}$ & $\begin{array}{l}5.9 \\
(8)\end{array}$ \\
\hline Abstinence* & Moderate & $\begin{array}{l}4.4 \\
(6)\end{array}$ & $\begin{array}{l}4.4 \\
(6)\end{array}$ \\
\hline Moderate & Abstinence* & $\begin{array}{l}11.8 \\
(16)\end{array}$ & $\begin{array}{l}11.8 \\
(16)\end{array}$ \\
\hline Abstinence* & Abstinence* & $\begin{array}{l}39.7 \\
(54)\end{array}$ & $\begin{array}{l}39.7 \\
(54)\end{array}$ \\
\hline Excessive & Abstinence* & $\begin{array}{l}6.6 \\
(9)\end{array}$ & $\begin{array}{l}6.6 \\
(9)\end{array}$ \\
\hline Abstinence* & Excessive & $\begin{array}{c}0 \\
(0)\end{array}$ & $\begin{array}{c}0 \\
(0)\end{array}$ \\
\hline
\end{tabular}

*Non-contradicting self-reported abstinence according to SOHT [11] 

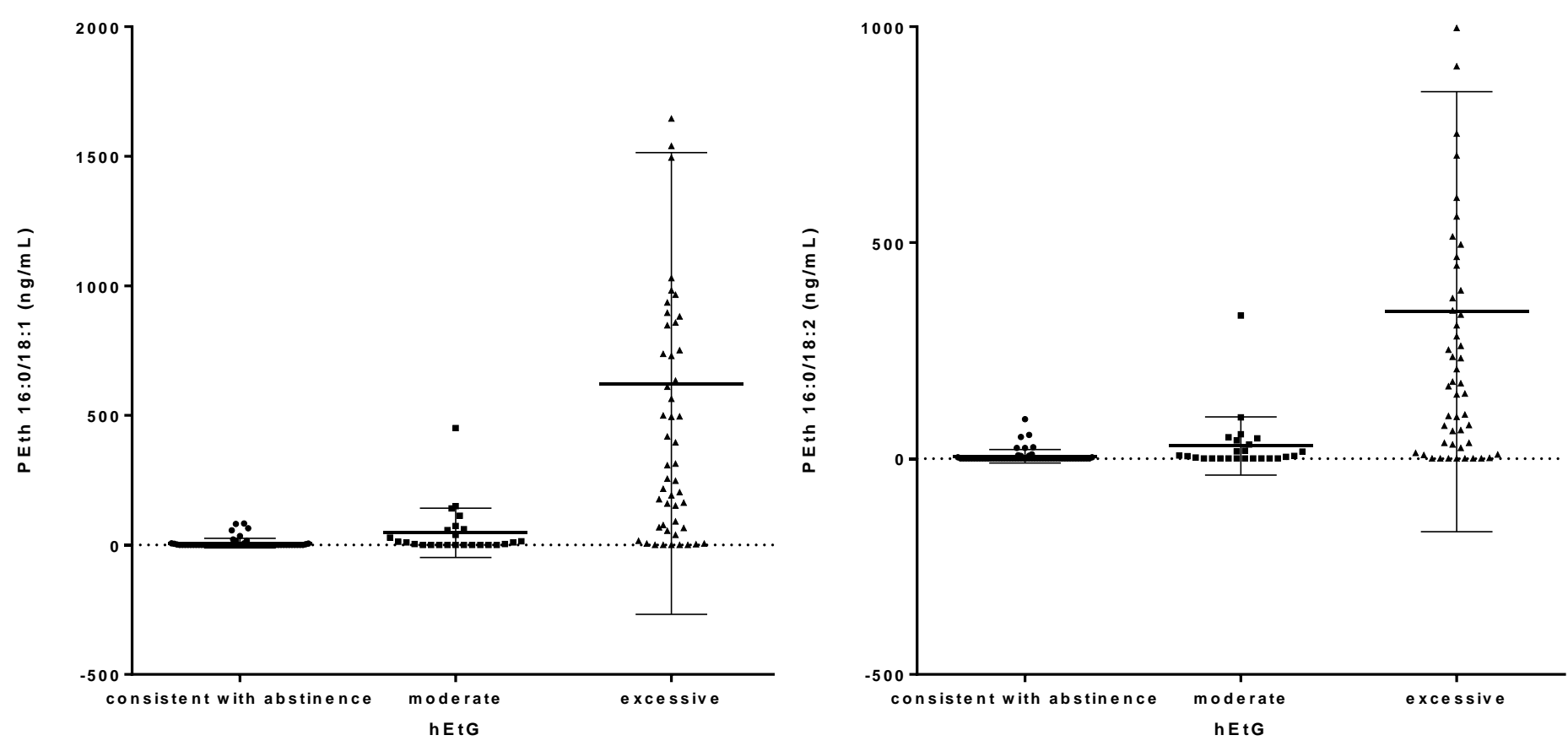

Figure 2. Classification of PEth 16:0/18:1 and 16:0/18:2 results in comparison to hEtG (Consistent with abstinence: $\mathrm{hEtG}<7 \mathrm{pg} / \mathrm{mg}$; moderate: $7 \leq \mathrm{hEtG}<30 \mathrm{pg} / \mathrm{mg}$; excessive: $\mathrm{hEtG} \geq 30 \mathrm{pg} / \mathrm{mg}$ ). Three data points (PEth 16:0/18:1 and PEth 16:0/18.2, respectively) are outside the axis limit in the column of excessive hEtG (1. PEth 16:0/18:1: $2155 \mathrm{ng} / \mathrm{mL}$, PEth 16:0/18:2: 1495 ng/mL; 2. PEth 16:0/18:1: 3545 ng/mL, PEth 16:0/18:2: 1945 ng/mL; 3. PEth 16:0/18:1: $4870 \mathrm{ng} / \mathrm{mL}$, PEth 16:0/18:2: $2685 \mathrm{ng} / \mathrm{mL}$ ). 

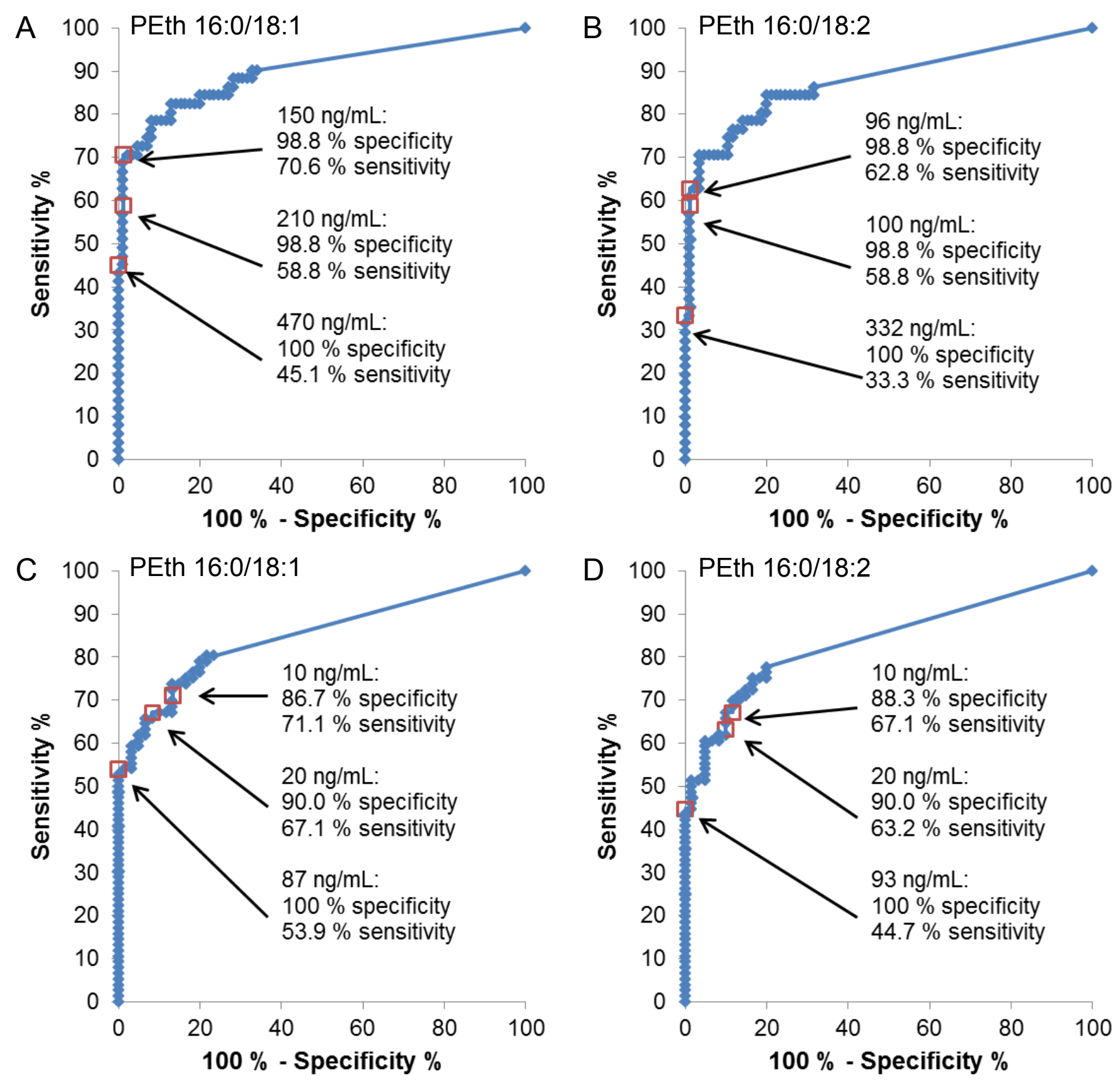

Figure 3. ROC analysis for PEth vs. hEtG. A: PEth 16:0/18:1 vs. hEtG to differentiate excessive from moderate alcohol consumption (AUROC 0.899, P value < 0.0001). B: PEth 16:0/18:2 vs. hEtG to differentiate excessive from moderate alcohol consumption (AUROC 0.876, $\mathrm{P}$ value < 0.0001). C: PEth 16:0/18:1 vs. hEtG to differentiate abstinence from moderate alcohol consumption (AUROC 0.85, P value < 0.0001). D: PEth 16:0/18:2 vs. hEtG to differentiate abstinence from moderate alcohol consumption (AUROC 0.84, P value < $0.0001)$. 


\section{References}

1. Schröck A, Hernandez Redondo A, Martin Fabritius M, König S, Weinmann W (2016) Phosphatidylethanol (PEth) in blood samples from "driving under the influence" cases as indicator for prolonged excessive alcohol consumption. Int J Legal Med 130(2): p. 393-400

2. The Federal Authorities of the Swiss Confederation (19. Dezember 1958 (effective: 20. May 2015)) Road Traffic Act Art. 15d. https://www.admin.ch/opc/de/classifiedcompilation/19580266/index.html Accessed 22. February 2016

3. Schweizerische Gesellschaft für Rechtsmedizin (SGRM) (2014) Bestimmung von Ethylglucuronid (EtG) in Haarproben. http://www.sgrm.ch/uploads/media/EtG_FINAL_2014.pdf Accessed 19 January 2016

4. Wurst FM, Yegles M, Alling C, Aradottir S, Dierkes J, Wiesbeck GA, Halter CC, Pragst F, Auwaerter V (2008) Measurement of direct ethanol metabolites in a case of a former driving under the influence (DUI) of alcohol offender, now claiming abstinence. Int J Legal Med 122(3): p. 235-9

5. Seidl S, Wurst FM, Alt A (2001) Ethyl glucuronide-a biological marker for recent alcohol consumption. Addict Biol 6(3): p. 205-212

6. Schwab N, Skopp G (2014) Identification and preliminary characterization of UDPglucuronosyltransferases catalyzing formation of ethyl glucuronide. Anal Bioanal Chem 406(9-10): p. 2325-32

7. Bendroth P, Kronstrand R, Helander A, Greby J, Stephanson N, Krantz P (2008) Comparison of ethyl glucuronide in hair with phosphatidylethanol in whole blood as post-mortem markers of alcohol abuse. Forensic Sci Int 176(1): p. 76-81

8. Schröck A, Thierauf A, Wurst FM, Thon N, Weinmann W (2014) Progress in monitoring alcohol consumption and alcohol abuse by phosphatidylethanol. Bioanalysis 6(17): p. 2285-94

9. Wurst FM, Thon N, Yegles M, Schröck A, Preuss UW, Weinmann W (2015) Ethanol Metabolites: Their Role in the Assessment of Alcohol Intake. Alcohol Clin Exp Res 39(11): p. 2060-72

10. Society of Hair Testing (SOHT) (2011) Consensus of the Society of Hair Testing on hair testing for chronic excessive alcohol consumption 2011.

http://www.soht.org/images/pdf/Revised\%20Alcohol\%20marker\%20Consensus.pdf. Accessed 15 April 2014 
11. Society of Hair Testing (SOHT) (2012) Use of Alcohol Markers in Hair for Abstinence Assessment 2012.

http://www.soht.org/images/pdf/Use\%20of\%20Alcohol\%20Markers\%20in\%20Hair\% 20for\%20Abstinence\%20Assessment\%202012.pdf. Accessed 15 April 2014

12. Society of Hair Testing (SOHT) (2014) 2014 Consensus for the Use of Alcohol Markers in Hair for Assessment of both Abstinence and Chronic Excessive Alcohol Consumption.

http://www.soht.org/images/pdf/2014\%20Alcohol\%20markers\%20revision\%2013JU N14\%20FINAL.pdf. Accessed 05 April 2016

13. Gnann H, Weinmann W, Engelmann C, Wurst FM, Skopp G, Winkler M, Thierauf A, Auwarter V, Dresen S, Ferreiros Bouzas N (2009) Selective detection of phosphatidylethanol homologues in blood as biomarkers for alcohol consumption by LC-ESI-MS/MS. J Mass Spectrom 44(9): p. 1293-9

14. Gnann H, Weinmann W, Thierauf A (2012) Formation of phosphatidylethanol and its subsequent elimination during an extensive drinking experiment over 5 days. Alcohol Clin Exp Res 36(9): p. 1507-11

15. Gnann H, Engelmann C, Skopp G, Winkler M, Auwarter V, Dresen S, Ferreiros N, Wurst FM, Weinmann W (2010) Identification of 48 homologues of phosphatidylethanol in blood by LC-ESI-MS/MS. Anal Bioanal Chem 396(7): p. 2415-23

16. Isaksson A, Walther L, Hansson T, Andersson A, Alling C (2011) Phosphatidylethanol in blood (B-PEth): A marker for alcohol use and abuse. Drug Test Anal 3(4): p. 195-200

17. Varga A, Hansson P, Johnson G, Alling C (2000) Normalization rate and cellular localization of phosphatidylethanol in whole blood from chronic alcoholics. Clin Chim Acta 299(1-2): p. 141-50

18. Kobayashi M, Kanfer JN (1987) Phosphatidylethanol formation via transphosphatidylation by rat brain synaptosomal phospholipase D. J Neurochem 48(5): p. 1597-603

19. Viel G, Boscolo-Berto R, Cecchetto G, Fais P, Nalesso A, Ferrara SD (2012) Phosphatidylethanol in blood as a marker of chronic alcohol use: a systematic review and meta-analysis. Int J Mol Sci 13(11): p. 14788-812

20. Winkler M, Skopp G, Alt A, Miltner E, Jochum T, Daenhardt C, Sporkert F, Gnann H, Weinmann W, Thierauf A (2013) Comparison of direct and indirect alcohol markers 
with PEth in blood and urine in alcohol dependent inpatients during detoxication. Int $\mathbf{J}$ Legal Med 127(4): p. 761-8

21. Aradottir S, Asanovska G, Gjerss S, Hansson P, Alling C (2006) Phosphatidylethanol (PEth) concentrations in blood are correlated to reported alcohol intake in alcoholdependent patients. Alcohol Alcohol 41(4): p. 431-7

22. Nanau RM, Neuman MG (2015) Biomolecules and Biomarkers Used in Diagnosis of Alcohol Drinking and in Monitoring Therapeutic Interventions. Biomolecules 5(3): p. $1339-85$

23. Mann K, Hoch E, Batra A, on behalf of the guideline working group (2016) S3Leitlinie "Screening, Diagnose und Behandlung alkoholbezogener Störungen" AWMF-Register Nr. 076-001. http://www.awmf.org/uploads/tx_szleitlinien/0760011_S3-Leitlinie_Alkohol_2016-02.pdf. Accessed 08.03.2016

24. Gnann H (2011) Phosphatidylethanol - Ein Alkoholkonsummarker auf dem Weg in die klinisch-forensische Routinediagnostik. Dissertation, University of Freiburg, Germany. http://www.freidok.unifreiburg.de/volltexte/8428/pdf/Diss_Heike_Gnann.pdf. Accessed 15 April 2014: p. 101

25. Schröck A, Thierauf-Emberger A, Schürch S, Weinmann W (2016) Phosphatidylethanol (PEth) detected in blood for 3 to 12 days after single consumption of alcohol - a drinking study with 16 volunteers. Int J Legal Med submitted in February 2016

26. Kummer N, Wille SM, Di Fazio V, Ramirez Fernandez Mdel M, Yegles M, Lambert WE, Samyn N (2015) Impact of the grinding process on the quantification of ethyl glucuronide in hair using a validated UPLC-ESI-MS-MS method. J Anal Toxicol 39(1): p. 17-23

27. Helander A, Hansson T (2013) [National harmonization of the alcohol biomarker PEth]. Lakartidningen 110(39-40): p. 1747-8

28. Pianta A, Liniger B, Baumgartner MR (2013) Ethyl glucuronide in scalp and non-head hair: an intra-individual comparison. Alcohol Alcohol 48(3): p. 295-302 